\title{
Consequences of continuing renin angiotensin aldosterone system antagonists in the preoperative period: a systematic review and meta-analysis
}

Qiong Ling ${ }^{1 \dagger}$, Yu Gu${ }^{2+}$, Jiaxin Chen ${ }^{2 \dagger}$, Yansheng Chen ${ }^{1}$, Yongyong Shi ${ }^{1}$, Gaofeng Zhao ${ }^{1 *}$ and Qianqian Zhu ${ }^{2^{*}}$ (D)

\begin{abstract}
Background: Patients who use angiotensin-converting enzyme inhibitors (ACEls)/angiotensin II receptor blockers (ARBs) are prone to developing side effects like hypotension and even refractory hypotension during anesthesia use, and whether ACEIs/ARBs should be continued or discontinued in such patients remains debatable. The present systematic review and meta-analysis was conducted to clarify the consequences of continuing or withholding these drugs, especially with regards to the incidence of intraoperative hypotension, in patients who continue to use ACEls/ARBs on the day of their scheduled surgery.
\end{abstract}

Methods: Studies with data pertinent to the incidence of intraoperative hypotension during anesthesia use in patients who continued the use of ACEIs/ARBs on the day of their scheduled surgery were considered for inclusion.

Results: Thirteen studies reporting on the incidences of intraoperative hypotension between patients who continued receiving ACEIs/ARBs and those who did not on the day of their surgical procedure were included. The pooled effects showed that hypotension during anesthesia was more likely to develop in patients who continued to take ACEIs/ARBs when compared to those who did not ( $\mathrm{RR}=1.41,95 \% \mathrm{Cl}$ : 1.21-1.64). However, there were no significant differences between these groups of patients with regards to postoperative complications including ST-T abnormalities, myocardial injury, myocardial infarction, stroke, major adverse cardiac events, acute kidney injury, or death $(\mathrm{RR}=1.25,95 \% \mathrm{Cl}$ : 0.76-2.04). The differences remained similar in subgroup analyses and sensitivity analyses.

Conclusions: No sufficient available evidence to recommend discontinuing ACEIs/ARBs on the day of surgery was found in this literature review and meta-analysis. However, anesthetists should be cautious about the risk for intraoperative hypotension in patients chronically receiving ACEIs/ARBs, and should know how to treat it effectively.

Keywords: Angiotensin-converting enzyme inhibitors (ACEls), Angiotensin II receptor blockers (ARBs), Intraoperative hypotension

\footnotetext{
* Correspondence: zhaogaofeng_97@163.com;

zhu.qian.qian123@stu.xjtu.edu.cn

${ }^{\dagger}$ Equal contributors

'Department of Anesthesiology, The Second Affiliated Hospital of

Guangzhou University of Chinese Medicine, Guangzhou City 510120,

People's Republic of China

${ }^{2}$ Department of Anesthesiology, The Third Affiliated Hospital of Sun Yat-Sen

University, Guangzhou City, Guangdong Province 510630, People's Republic

of China
} 


\section{Background}

An increasing number of patients who have hypertension and chronic heart diseases continue to be scheduled for elective surgery. However, for those patients who use angiotensin-converting enzyme inhibitors (ACEIs)/angiotensin II receptor blockers (ARBs), the question of whether these medications should be continued or discontinued on the day of surgery remains under discussion [1]. ACEIs/ARBs are not only widely used as antihypertensive medications, but also for treating chronic heart diseases or other diseases, such as diabetic nephropathy [2]. Furthermore, the use of ACEIs/ARBs has shown various beneficial effects [3, 4].

However, patients using ACEIs/ARBs have been reported to be prone to side effects like hypotension and even refractory hypotension during the administration of anesthesia [5, 6]. Therefore, some anesthetists have suggested the possibility of discontinuing these drugs in order to maintain the patient's hemodynamic stability during surgery $[7,8]$. However, other research has shown that the discontinuation of ACEIs/ARBs preoperatively did not decrease the incidence of hypotension, and that the recommendation of discontinuing ACEIs/ARBs should be taken with reservations $[9,10]$. One study indicated that patients who discontinued these drugs on the day of surgery required more vasodilators to control hypertension after surgery [9]. Regardless of the predominant opinion, it is clear that the present concerns regarding continuing or discontinuing these drugs before surgery need to be explored. Besides being first-line antihypertensive drugs, these drugs also decrease morbidity and mortality, and prevent secondary strokes in patients with chronic heart diseases [11].

In order to clarify the consequences of continuing patients on ACEIs/ARBs on the day of their scheduled surgery, the present systematic review and meta-analysis was conducted.

\section{Methods}

\section{Search strategy}

The following electronic databases were searched: the Cochrane Library, PubMed, the Web of Knowledge, and Elsevier (ScienceDirect OnLine, SDOL) to retrieve studies investigating the incidence of hypotension in those patients continuously receiving ACEIs/ARBs, especially in patients continuing their use of ACEIs/ARBs on the day of their surgery.

Text headings and medical subject heading (MeSH) terms for the search included "angiotensin-converting enzyme inhibitors/ACEIs," "angiotensin II receptor blockers/ARBs," "angiotensin receptor antagonist," "reninangiotensin system (RAS)/RAS inhibitor," "renin-angiotensin aldosterone system (RAAS)/RAAS inhibitor," "hypotension," and "low blood pressure."
The search strategy included considering any terms pertinent to renin-angiotensin system/RAS inhibitors and any terms related to hypotension. Eligible trials were identified via electronic searches from 1981, when captopril, the first ACEI, was approved by the United States Food and Drug Administration, up to July 1, 2017. A hand-search method was used to examine the reference lists of some of the identified trials. The Preferred Reporting Items for Systematic Reviews and MetaAnalyses (PRISMA) guidelines were used to guide the meta-analysis.

\section{Inclusion and exclusion criteria}

Case-control studies, cohort studies, and/or randomized controlled trials were considered for inclusion if they met the following criteria: (i) written in the English language; (ii) enrolled adults scheduled for elective or emergency surgery who were chronically using ACEIs/ ARBs; and (iii) compared the incidence of hypotension during anesthesia in patients continuing to receive ACEIs/ARBs with those who did not receive these drugs on the day of surgery. The exclusion criteria were: (i) formatted as a letter, review or meeting abstract; (ii) containing a lack of hypotension data as incidences or numbers; and (iii) containing no delineation between patients continuing to receive ACEIs/ARBs and those who were not, or those who were using other drugs or who had never used antihypertensive drugs. Only published data were included in the present study.

\section{Data extraction}

The data were extracted independently by three reviewers (Qiong Ling, $\mathrm{Yu} \mathrm{Gu}$ and Jiaxin Chen) and validated by a fourth one (Qianqian Zhu). The following information was extracted from each included study: the name of the primary author, year of publication, geographical location, number of participants, type of surgery, and anesthesia.

\section{Statistical analysis}

The meta-analysis was performed in Review Manager 5 (The Cochrane Collaboration, Oxford, England). The pooled effect of continuing ACEI/ARB use on the incidence of hypotension during anesthesia use was demonstrated as relative risk (RR) with a 95\% confidence interval (CI). Subgroup analyses were used according to whether the study included patients chronically taking ACEIs/ARBs or not. Sensitivity analyses according to the type of included studies were also used. A chi-squared test was used to assess the heterogeneity. An $\mathrm{I}^{2}$ value of less than $25 \%$ was regarded as representing no heterogeneity. A random effects model was used when heterogeneity was found to exist among the studies analyzed. Begg's and Egger's tests were used to assess the 
publication bias, and were performed using Stata 12.1 (Stata Corp, College Station, TX, USA).

\section{Results}

\section{Characteristics of the included studies}

The search strategy yielded 2,429 non-duplicated entries. Thirteen studies were included in the final analysis [7, 9, 12-22]. The inclusion and exclusion processes of the studies are shown in Fig. 1.

Seven studies investigated the hypotension differences in patients who ceased taking ACEIs/ARBs on the day of surgery and those who did not. Six studies compared the incidences of hypotension between patients who continued receiving ACEIs/ARBs on the day of surgery and those who did not receive these drugs chronically. The details of the included studies are shown in Table 1 . The quality of observational studies was assessed with the use of the Newcastle-Ottawa Scale (NOS) [23] (Table 1).

\section{Meta-analyses}

Pooled effects showed that patients who continued taking ACEIs/ARBs on the day of surgery were more like to develop hypotension during anesthesia use $(\mathrm{RR}=1.41$, 95\% CI: 1.21-1.64; Fig. 2), in comparison with those who were not receiving the drugs. The subgroup analysis demonstrated that, in comparison with patients who continued taking ACEIs/ARBs on the day of surgery, hypotension during anesthesia was more prone to occur in patients who ceased taking the drugs prior to surgery $(\mathrm{RR}=1.45,95 \% \mathrm{CI}: 1.20-1.73$; Fig. 2$)$, but not in those who did not receive the drugs at baseline $(R R=1.40$, 95\% CI: 0.97-2.01; Fig. 2). The details of the heterogeneities between the studies are showed in Fig. 2.

However, notably, the definitions of hypotension were different in the different studies (Table 1).

\section{Postoperative complication}

Seven studies reported postoperative complications, including ST-T abnormalities, myocardial injury, myocardial infarction, stroke, major adverse cardiac events, acute kidney injury, or death (Table 1) [7, 12, 13, 15, 20-22]. There were no significant differences between patients who continued receiving ACEIs/ARBs and those who did not with regards to the postoperative complications mentioned above ( $R R=1.25$, 95\% CI: 0.76-2.04; Fig. 3). The differences remained similar in the subgroup analyses (Fig. 3).

It was observed that there were no significant differences in the prevalence of cardiac complications, including myocardial injury, myocardial infarctions, and major adverse cardiac events, between the patients who continued receiving ACEIs/ARBs and those who did not $(R R=1.23$, 95\% CI: 0.82-1.85; Fig. 4).

\section{Subgroup and sensitivity analyses}

The results of subgroup and sensitivity analyses are list in Table 2.

It was observed that there were no significant differences in the prevalence of postoperative complications or cardiac complications, between the patients who

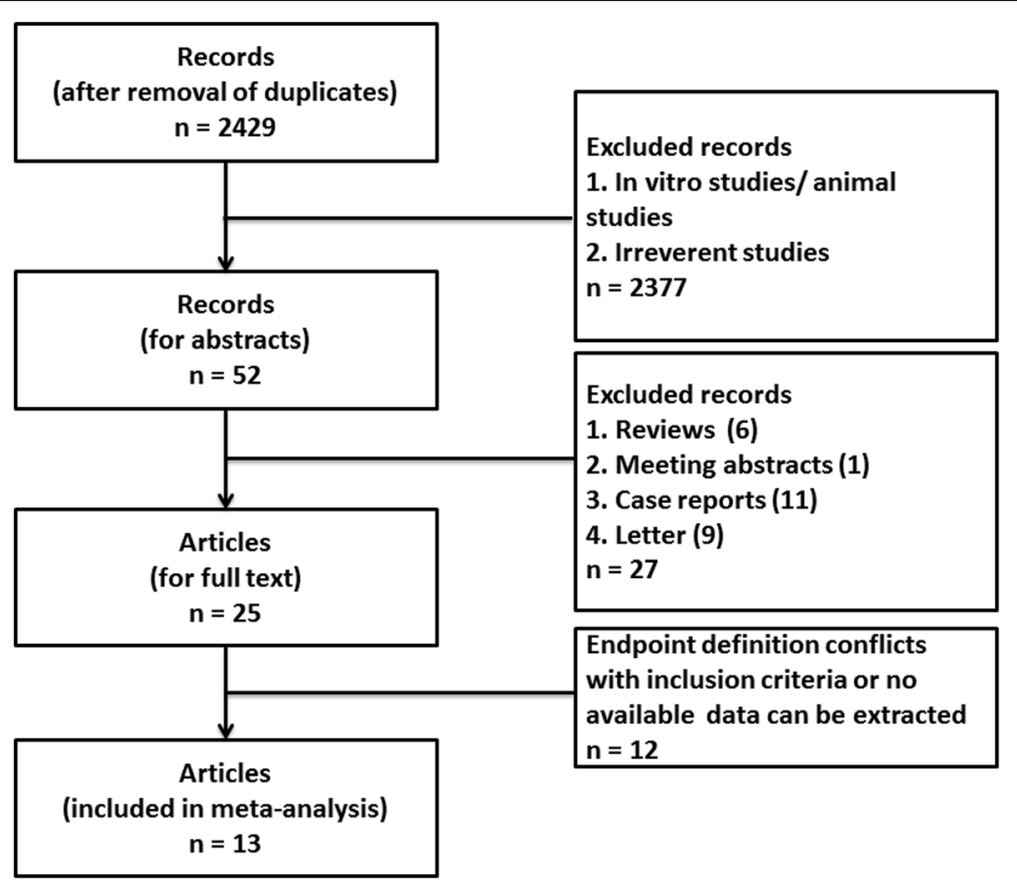

Fig. 1 The flow chart of inclusion and exclusion 


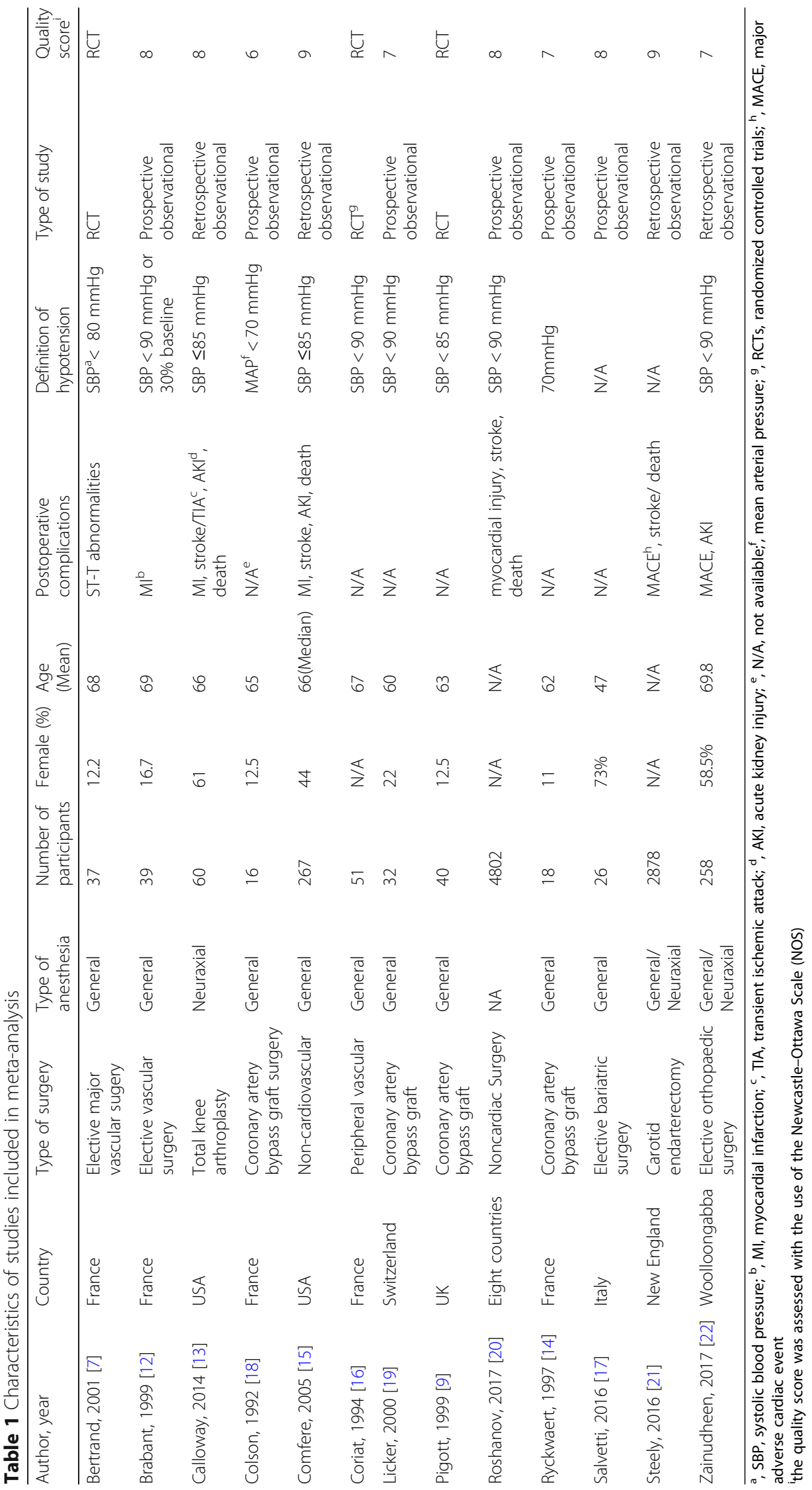




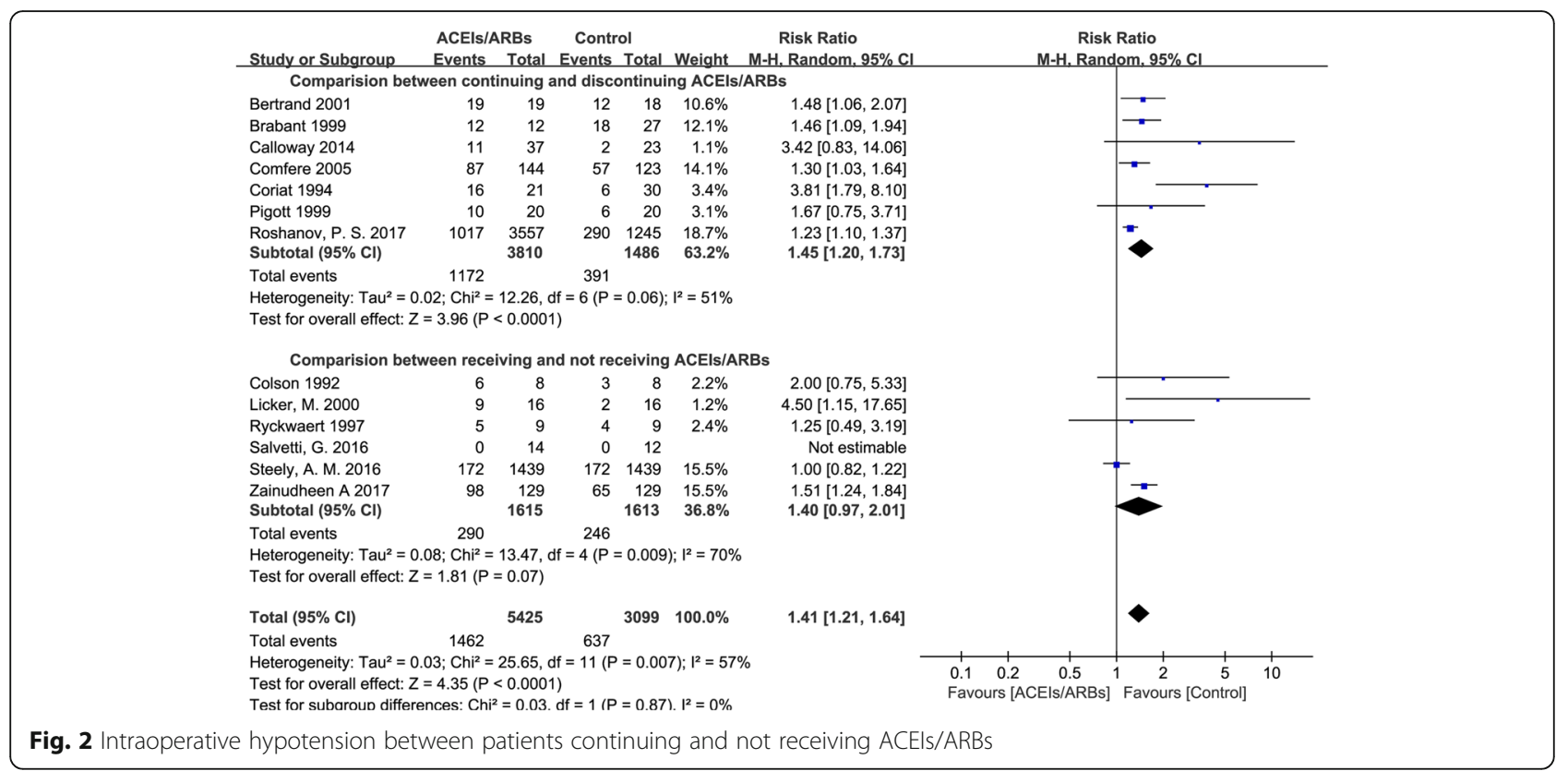

continued receiving ACEIs/ARBs and those who did not in all subgroup and sensitivity analyses.

\section{Publication bias}

Begg's and Egger's tests were used to assess the publication bias for all the included studies. No significant publication bias was found ( $p>0.05$ for both tests).

\section{Discussion}

Based on the available data, the present systematic review and meta-analysis of 13 studies demonstrated that patients who continued taking ACEIs/ARBs on the day of their surgery were more likely than those who did not, to develop hypotension during anesthesia. However, receiving ACEIs/ARBs on the day of surgery did not increase the incidences of noted postoperative complications, including myocardial infarction, stroke, acute kidney injury, and death. The subgroup and sensitivity analyses showed that the association is similar only when comparing the patients who ceased taking ACEIs/ARBs prior to surgery with those who continued taking the drugs.

RAAS antagonists or ACEIs/ARBs, are the first-line drugs for the treatment of hypertension and chronic heart failure. Because intraoperative hemodynamic instability, especially refractory hypotension, has been observed in patients who have been treated chronically with ACEIs/ARBs [24-26], some researchers have suggested discontinuing these drugs on the day of surgery $[7,8]$. RAAS antagonists play a major role in regulating

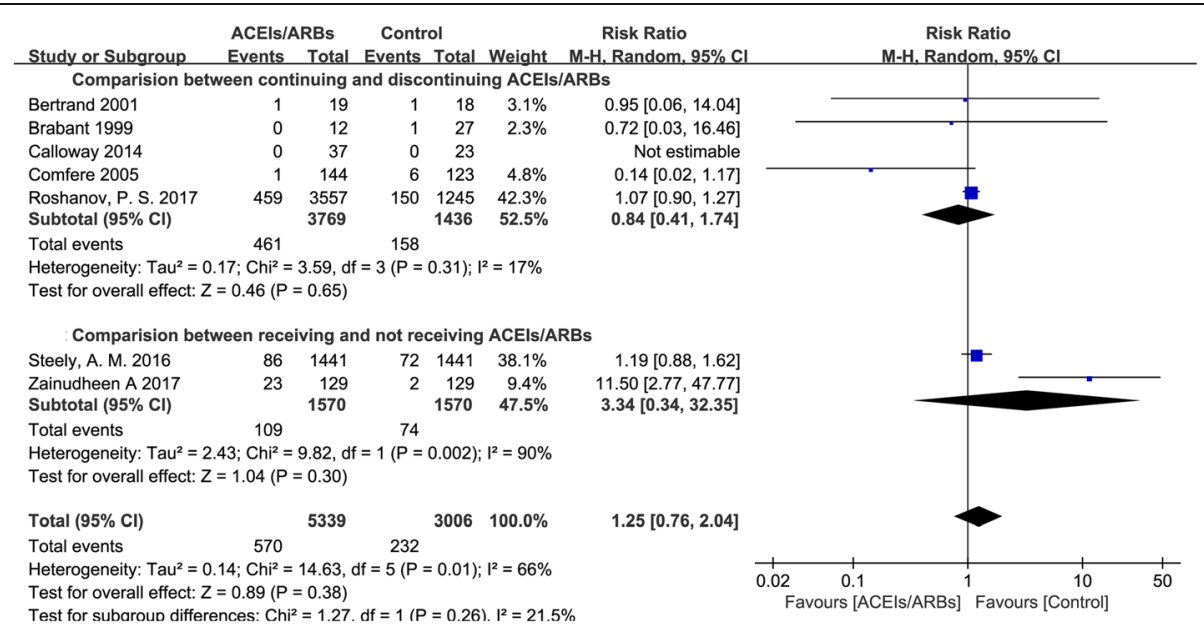

Fig. 3 Postoperative complications between patients continuing and not receiving ACEIs/ARBs 


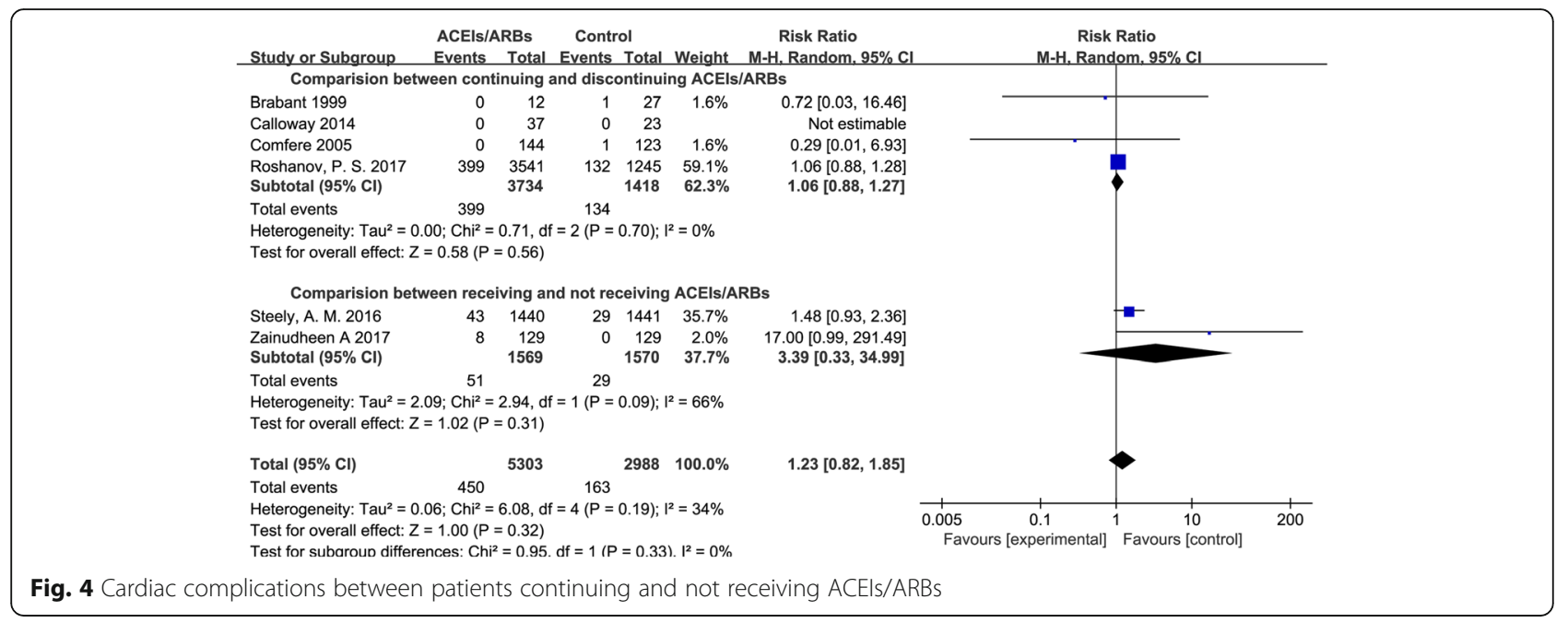

and maintaining normal blood pressure, especially during general anesthesia use [27] Additionally, some researchers have suggested that ACEIs/ARBs reduce the adrenergic vasoconstrictive response [19]. This might partly explain why ACEI/ARB-associated hypotension was refractory and resistant to phenylephrine, ephedrine, and norepinephrine $[6,28]$. However, severe or refractory hypotension during anesthesia administration in patients chronically receiving ACEIs/ARBs has only been reported in several cases $[24,25]$. In most cases, hypotension was sensitive to intravenous fluid infusion and vasoconstrictors, and continuing ACEIs/ARBs on the day of surgery did not increase the incidence of severe or refractory hypotension. Terlipressin is known to be effective in rapidly correcting refractory hypotension, even after the failure of ephedrine in patients chronically treated with ACEIs/ARBs, without impairing left ventricular function $[29,30]$.

The most concerning factor of hypotension is the occurrence of ischemia-related events, including myocardial injury, myocardial infarction, stroke, and acute kidney injury. However, the results of the present study showed that continuing ACEIs/ARBs on the day of surgery did not increase the incidence of postoperative complications such as myocardial injury, myocardial infarction, stroke, acute kidney injury, or death. In line with the present study, another recent study conducted in eight countries also demonstrated that intraoperative hypotension was not significantly associated with the composite outcome of death, myocardial injury, or stroke within the 30 days after surgery [20]. Furthermore, several myocardial infarctions were reported in patients who discontinued the use of ACEIs/ARBs, though a previous meta-analysis showed that there was no more risk of postoperative myocardial infarction in patients continuing than in those discontinuing ACEIs/ ARBs preoperatively [31]. ACEIs/ARBs may protect patients from myocardial infarction, cardiovascular mortality, and morbidity, which might be attributed to the ability of these drugs to prevent ventricular remodeling and improving left ventricular function [3, 32]. A previous study suggested an association between

Table 2 Results of subgroup and sensitivity analyses

\begin{tabular}{|c|c|c|c|}
\hline & RR and $\mathrm{I}^{\mathrm{b}}$ for hypotension & RR and $\mathrm{I}^{\mathrm{b}}$ all complications & RR and $\mathrm{I}^{\mathrm{b}}$ all cardiac complications \\
\hline \multicolumn{4}{|l|}{ Subgroup analyses } \\
\hline Results of orthopaedic surgery surgery & $1.70(0.95-3.04), 26 \%$ & $N / A^{a}$ & N/A \\
\hline Results of cardiac surgery & $2.00(1.23-3.26), 0 \%$ & N/A & N/A \\
\hline Results of noncardiac surgery & $1.37(1.17-1.61), 67 \%$ & $1.25(0.76-2.04), 66 \%$ & $1.23(0.82-1.85), 34 \%$ \\
\hline Results of vascular surgery & $1.51(1.02-2.23), 82 \%$ & 1.18(0.88-1.60), 0\% & $1.46(0.92-2.31), 0 \%$ \\
\hline \multicolumn{4}{|l|}{ Sensitivity analyses } \\
\hline Results of RCTs ${ }^{\mathrm{b}}$ & $2.01(1.07-3.77), 68 \%$ & N/A & N/A \\
\hline Results of prospective observational studies & $1.35(1.11-1.66), 26 \%$ & $1.07(0.90-1.27), 0 \%$ & $1.06(0.88-1.28), 0 \%$ \\
\hline Results of retrospective observational studies & $1.29(0.99-1.69), 73 \%$ & $1.42(0.22-9.24), 85 \%$ & $1.87(0.35-10.06), 85 \%$ \\
\hline
\end{tabular}

${ }^{\mathrm{a}}$, NA not available, ${ }^{\mathrm{b}}, R C T$ s randomized controlled trials 
uninterrupted reception of ACEIs/ARBs and a reduction in ischemia-related myocardial cell injury in cardiac surgery [33]. Therefore, some experts recommend that these drugs should not be discontinued before surgery [34]. Furthermore, treatment with ACEIs/ARBs after acute myocardial infarction was associated with improved long-term survival and low rates of adverse renal events [35].

To date, there has been no large randomized controlled trial (RCT) that explores the long-term effects of discontinuing ACEIs/ARBs. Furthermore, no serious outcomes have occurred, though some intraoperative refractory hypotension cases were reported in patients continuing the use of ACEIs/ARBs on the day of surgery in the current literature. Refractory hypotension could be treated efficiently by a combination of fluid infusion and vasoconstrictors, especially terlipressin [36]. Therefore, in order to avoid a drug holiday and forgetting to restart using the drugs, physicians should be cautious when recommending that these drugs be discontinued.

\section{Strengths and limitations}

There are some limitations in the present meta-analysis. First, the included studies varied in design and quality, and no RCT was identified that involved a large number of participants. Though a recent study conducted in eight countries involved many patients, it was an observational study [20]. Many potential confounders might limit the statistical power of the results of that study. Secondly, the definition of hypotension or refractory hypotension was not consistent in each study, which might lead to bias of the results. Furthermore, there were no data on the long-term effects of continuing or discontinuing ACEIs/ARBs on the day of surgery, though several studies reported the occurrence of myocardial infarction based on troponin levels and electrocardiogram findings in a short time after surgery, and one study reported postoperative death $[12,16]$. Therefore, the above mentioned factors might weaken the results of the present study.

\section{Conclusion}

In conclusion, the data available at the time this study was conducted did not provide sufficient evidence to support that continuing ACEIs/ARBs on the day of surgery in patients who chronically received these drugs is associated with obvious disadvantages. No significant incidences of severe or refractory hypotension or postoperative ischemia-related complications were observed between those patients continuing ACEIs/ARBs and those who either discontinued these drugs or continued using other antihypertensive drugs. Therefore, evidence supporting the discontinuation of ACEIs/ARBs on the day of surgery is lacking. However, anesthetists should be cautious about the possibility of hypotension in patients chronically receiving ACEIs/ARBs, and should know how to treat it effectively. To explore the longterm effects of continuing or discontinuing ACEIs/ARBs in patients, RCTs involving a large number of patients are required.

\section{Abbreviations \\ ACEls: Angiotensin-converting enzyme inhibitors;" ARBs: Angiotensin II receptor blockers; Cl: Confidence interval; RAAS: Renin-angiotensin aldosterone system; RAS: Renin-angiotensin system; RR: Relative risk}

\section{Acknowledgements}

The authors thank the contributions made by Zhengwen Liu form First Affiliated Hospital of Xi'an Jiaotong University, for careful proofreading of this manuscript.

\section{Funding}

The present study was supported by National Natural Science Foundation of China (No. 81600507).

\section{Availability of data and materials}

All data generated or analyzed during this study are included in this published article.

\section{Authors' contributions}

QZ designed the study. The literature search, screened and reviewed for eligibility was performed by QL, YG and JC independently. The data analyses were performed by QL, YG, JC, YC and YS. The manuscript was drafted by QZ and GZ. YC and YS critically reviewed and edited the manuscript. All authors read and approved the final manuscript.

Ethics approval and consent to participate Not applicable.

\section{Consent for publication}

Not applicable.

\section{Competing interests}

The authors declare that they have no competing interests.

\section{Publisher's Note}

Springer Nature remains neutral with regard to jurisdictional claims in published maps and institutional affiliations.

Received: 9 August 2017 Accepted: 6 February 2018

Published online: 26 February 2018

\section{References}

1. Bogebjerg MK. No consensus on withholding angiotensin-converting enzyme inhibitors and angiotensin receptor blockers before spinal anaesthesia. Dan Med J. 2012:59(12):A4543.

2. Bohm M. Angiotensin receptor blockers versus angiotensin-converting enzyme inhibitors: where do we stand now? Am J Cardiol. 2007; 100(3A):38J-44J.

3. Garg R, Yusuf S. Overview of randomized trials of angiotensin-converting enzyme inhibitors on mortality and morbidity in patients with heart failure. Collaborative group on ACE inhibitor trials. JAMA. 1995;273(18):1450-6.

4. Yang CW, Tzeng NS, Yin YJ, Li CH, Chen HA, Chiu SH, Ho SY, Huang HL. Angiotensin receptor blockers decrease the risk of major adverse cardiovascular events in patients with end-stage renal disease on maintenance dialysis: a Nationwide matched-cohort study. PLoS One. 2015; 10(10):e0140633.

5. Kheterpal S, Khodaparast O, Shanks A, O'Reilly M, Tremper KK. Chronic angiotensin-converting enzyme inhibitor or angiotensin receptor blocker therapy combined with diuretic therapy is associated with increased episodes of hypotension in noncardiac surgery. J Cardiothorac Vasc Anesth. 2008;22(2):180-6. 
6. Nabbi R, Woehlck HJ, Riess ML. Refractory hypotension during general anesthesia despite preoperative discontinuation of an angiotensin receptor blocker. F1000Res. 2013;2:12.

7. Bertrand M, Godet G, Meersschaert K, Brun L, Salcedo E, Coriat P. Should the angiotensin II antagonists be discontinued before surgery? Anesth Analg. 2001:92(1):26-30.

8. Twersky RS, Goel V, Narayan P, Weedon J. The risk of hypertension after preoperative discontinuation of angiotensin-converting enzyme inhibitors or angiotensin receptor antagonists in ambulatory and same-day admission patients. Anesth Analg. 2014;118(5):938-44.

9. $\quad$ Pigott DW, Nagle C, Allman K, Westaby S, Evans RD. Effect of omitting regular ACE inhibitor medication before cardiac surgery on haemodynamic variables and vasoactive drug requirements. Br J Anaesth. 1999;83(5):715-20.

10. da Costa W, Caldas AC, Nunes LG, Beraldo PS, Saraiva RA. Influence of angiotensin-converting enzyme inhibitors on hypotension after anesthetic induction: is the preoperative discontinuation of this drug necessary? Rev Bras Anestesiol. 2009;59(6):704-15

11. Yusuf S, Sleight P, Pogue J, Bosch J, Davies R, Dagenais G. Effects of an angiotensin-converting-enzyme inhibitor, ramipril, on cardiovascular events in high-risk patients. The heart outcomes prevention evaluation study investigators. N Engl J Med. 2000;342(3):145-53.

12. Brabant $S M$, Bertrand M, Eyraud D, Darmon PL, Coriat P. The hemodynamic effects of anesthetic induction in vascular surgical patients chronically treated with angiotensin II receptor antagonists. Anesth Analg. 1999;89(6):1388-92.

13. Calloway JJ, Memtsoudis SG, Krauser DG, Ma Y, Russell LA, Goodman SM. Hemodynamic effects of angiotensin inhibitors in elderly hypertensives undergoing total knee arthroplasty under regional anesthesia. J Am Soc Hypertens. 2014;8(9):644-51.

14. Ryckwaert F, Colson P. Hemodynamic effects of anesthesia in patients with ischemic heart failure chronically treated with angiotensin-converting enzyme inhibitors. Anesth Analg. 1997:84(5):945-9.

15. Comfere T, Sprung J, Kumar MM, Draper M, Wilson DP, Williams BA, Danielson $D R$, Liedl L, Warner DO. Angiotensin system inhibitors in a general surgical population. Anesth Analg. 2005;100(3):636-44. table of contents

16. Coriat P, Richer C, Douraki T, Gomez C, Hendricks K, Giudicelli JF, Viars P. Influence of chronic angiotensin-converting enzyme inhibition on anesthetic induction. Anesthesiology. 1994;81(2):299-307.

17. Salvetti G, Di Salvo C, Ceccarini G, Abramo A, Fierabracci P, Magno S, Piaggi $P$, Vitti P, Santini F. Chronic renin-angiotensin system (RAS) blockade may not induce hypotension during Anaesthesia for bariatric surgery. Obes Surg. 2016;26(6):1303-7

18. Colson P, Saussine M, Seguin JR, Cuchet D, Chaptal PA, Roquefeuil B. Hemodynamic effects of anesthesia in patients chronically treated with angiotensin-converting enzyme inhibitors. Anesth Analg. 1992;74(6):805-8.

19. Licker M, Schweizer A, Hohn L, Farinelli C, Morel DR. Cardiovascular responses to anesthetic induction in patients chronically treated with angiotensin-converting enzyme inhibitors. Can J Anaesth. 2000;47(5):433-40.

20. Roshanov PS, Rochwerg B, Patel A, Salehian O, Duceppe E, Belley-Cote EP, Guyatt GH, Sessler Dl, Le Manach Y, Borges FK, et al. Withholding versus continuing angiotensin-converting enzyme inhibitors or angiotensin ॥ receptor blockers before noncardiac surgery: an analysis of the vascular events in noncardiac surgery patlents cOhort evaluatioN prospective cohort. Anesthesiology. 2017;126(1):16-27.

21. Steely AM, Callas PW, Bertges DJ. Renin-angiotensin-aldosterone-system inhibition is safe in the preoperative period surrounding carotid endarterectomy. J Vasc Surg. 2016;63(3):715-21.

22. Zainudheen A, Scott IA, Caney X. Association of renin angiotensin antagonists with adverse perioperative events in patients undergoing elective orthopaedic surgery: a case-control study. Intern Med J. 2017;47(9):999-1005.

23. Wells G, Shea B, O'Connell J: The Newcastle-Ottawa Scale (NOS) for Assessing The Quality of Nonrandomised Studies in Meta-analyses. (http://www.ohri.ca/programs/clinical_epidemiology/oxford.asp). Accessed 15 Nov 2017.

24. Akinci SB, Ayhan B, Kanbak M, Aypar U. Refractory hypotension in a patient chronically treated with a long acting angiotensin-converting enzyme inhibitor. Anaesth Intensive Care. 2004:32(5):722-3.

25. Cozanitis DA. The importance of interrupting angiotensin converting enzyme inhibitor treatment before spinal anaesthesia-a controlled case report. Anaesthesiol Reanim. 2004;29(1):16-8.

26. Trotter J. Catecholamine-resistant hypotension following induction for spinal exploration. AANA J. 2012;80(1):55-60.
27. Colson P, Ryckwaert F, Coriat P. Renin angiotensin system antagonists and anesthesia. Anesth Analg. 1999:89(5):1143-55.

28. Licker M, Neidhart $P$, Lustenberger $S$, Valloton MB, Kalonji T, Fathi M, Morel DR. Long-term angiotensin-converting enzyme inhibitor treatment attenuates adrenergic responsiveness without altering hemodynamic control in patients undergoing cardiac surgery. Anesthesiology. 1996;84(4):789-800.

29. Eyraud D, Brabant S, Nathalie D, Fleron MH, Gilles G, Bertrand M, Coriat P. Treatment of intraoperative refractory hypotension with terlipressin in patients chronically treated with an antagonist of the renin-angiotensin system. Anesth Analg. 1999;88(5):980-4.

30. Meersschaert K, Brun L, Gourdin M, Mouren S, Bertrand M, Riou B, Coriat P. Terlipressin-ephedrine versus ephedrine to treat hypotension at the induction of anesthesia in patients chronically treated with angiotensin converting-enzyme inhibitors: a prospective, randomized, double-blinded, crossover study. Anesth Analg. 2002:94(4):835-40. table of contents

31. Rosenman DJ, McDonald FS, Ebbert JO, Erwin PJ, LaBella M, Montori VM. Clinical consequences of withholding versus administering reninangiotensin-aldosterone system antagonists in the preoperative period. J Hosp Med. 2008;3(4):319-25.

32. Ricci F, Di Castelnuovo A, Savarese G, Perrone Filardi P, De Caterina R. ACEinhibitors versus angiotensin receptor blockers for prevention of events in cardiovascular patients without heart failure - a network meta-analysis. Int J Cardiol. 2016;217:128-34.

33. Boldt J, Rothe G, Schindler E, Doll C, Gorlach G, Hempelmann G. Can clonidine, enoximone, and enalaprilat help to protect the myocardium against ischaemia in cardiac surgery? Heart. 1996;76(3):207-13.

34. Tohmo H, Karanko M. Angiotensin-converting enzyme inhibitors and anaesthesia. Acta Anaesthesiol Scand. 1996;40(1):132-3.

35. Evans M, Carrero JJ, Szummer K, Akerblom A, Edfors R, Spaak J, Jacobson $\mathrm{SH}$, Andell $\mathrm{P}$, Lindhagen $\mathrm{L}$, Jernberg T. Angiotensin-converting enzyme inhibitors and angiotensin receptor blockers in myocardial infarction patients with renal dysfunction. J Am Coll Cardiol. 2016;67(14):1687-97.

36. Morelli A, Tritapepe L, Rocco M, Conti G, Orecchioni A, De Gaetano A, Picchini U, Pelaia P, Reale C, Pietropaoli P. Terlipressin versus norepinephrine to counteract anesthesia-induced hypotension in patients treated with renin-angiotensin system inhibitors: effects on systemic and regional hemodynamics. Anesthesiology. 2005;102(1):12-9.

\section{Submit your next manuscript to BioMed Central and we will help you at every step:}

- We accept pre-submission inquiries

- Our selector tool helps you to find the most relevant journal

- We provide round the clock customer support

- Convenient online submission

- Thorough peer review

- Inclusion in PubMed and all major indexing services

- Maximum visibility for your research

Submit your manuscript at www.biomedcentral.com/submit
) Biomed Central 